OPEN ACCESS

Edited by:

Steven Moran,

Universität Zürich, Switzerland

Reviewed by:

Søren Wichmann,

Universität Tübingen, Germany

Giuseppe Longobardi,

University of York, United Kingdom

*Correspondence:

Simon J. Greenhill greenhill@shh.mpg.de

Specialty section:

This article was submitted to

Language Sciences,

a section of the journal

Frontiers in Psychology

Received: 28 September 2017

Accepted: 05 April 2018

Published: 27 April 2018

Citation:

Greenhill SJ, Hua X, Welsh CF, Schneemann $H$ and Bromham $L$ (2018) Population Size and the Rate of

Language Evolution: A Test Across

Indo-European, Austronesian, and

Bantu Languages.

Front. Psychol. 9:576.

doi: 10.3389/fpsyg.2018.00576

\section{Population Size and the Rate of Language Evolution: A Test Across Indo-European, Austronesian, and Bantu Languages}

\author{
Simon J. Greenhill ${ }^{1,2 *}$, Xia Hua ${ }^{1,3}$, Caela F. Welsh ${ }^{3}$, Hilde Schneemann ${ }^{1,3}$ and \\ Lindell Bromham ${ }^{1,3}$ \\ ${ }^{1}$ ARC Centre of Excellence for the Dynamics of Language, Australian National University, Canberra, ACT, Australia, \\ ${ }^{2}$ Department of Linguistic and Cultural Evolution, Max Planck Institute for the Science of Human History (MPG), Jena, \\ Germany, ${ }^{3}$ Research School of Biology, Macroevolution and Macroecology, Australian National University, Canberra, ACT, \\ Australia
}

What role does speaker population size play in shaping rates of language evolution? There has been little consensus on the expected relationship between rates and patterns of language change and speaker population size, with some predicting faster rates of change in smaller populations, and others expecting greater change in larger populations. The growth of comparative databases has allowed population size effects to be investigated across a wide range of language groups, with mixed results. One recent study of a group of Polynesian languages revealed greater rates of word gain in larger populations and greater rates of word loss in smaller populations. However, that test was restricted to 20 closely related languages from small Oceanic islands. Here, we test if this pattern is a general feature of language evolution across a larger and more diverse sample of languages from both continental and island populations. We analyzed comparative language data for 153 pairs of closely-related sister languages from three of the world's largest language families: Austronesian, Indo-European, and Niger-Congo. We find some evidence that rates of word loss are significantly greater in smaller languages for the Indo-European comparisons, but we find no significant patterns in the other two language families. These results suggest either that the influence of population size on rates and patterns of language evolution is not universal, or that it is sufficiently weak that it may be overwhelmed by other influences in some cases. Further investigation, for a greater number of language comparisons and a wider range of language features, may determine which of these explanations holds true.

Keywords: language evolution, language phylogenies, computational historical linguistics, demography, population size, Galton's problem, phylogenetic independence

\section{INTRODUCTION}

The role of speaker population size in shaping patterns and rates of language and cultural evolution has been much discussed, but few generalities have been agreed upon. It has been suggested that larger populations should have higher rates of language change, because populations containing more individuals provide more opportunity for innovations to arise (Richerson et al., 2009; Kline and Boyd, 2010; Baldini, 2015). Large populations might also be less prone to 
random sampling effects that can cause elements of language and culture to be lost (Shennan, 2001; Henrich, 2004; Kline and Boyd, 2010; Collard et al., 2013) and they may have less stringent norm enforcement allowing them to change faster (Bowern, 2010; Trudgill, 2011). Larger populations might also have more robust transmission systems: having more people to learn from might increase fidelity of information transition (Derex et al., 2013), possibly because learners in large populations have a large set of potential models to learn from (Henrich, 2004; Kline and Boyd, 2010). Exposure to more people may make learning more robust, potentially allowing retention of a wider range of linguistic diversity (Trudgill, 2004; Hay and Bauer, 2007; Atkinson, 2011; Wichmann et al., 2011; Derex et al., 2013), although this effect is not universally supported (Caldwell and Millen, 2010; Read, 2012).

Other researchers have proposed that rates of change should be fastest in small populations due to the more rapid diffusion of new features (Nettle, 1999). Languages spoken by small speaker populations might be able to develop and retain greater linguistic complexity (Nettle, 2012). Smaller populations may have greater tolerance of diversity (Milroy and Milroy, 1985, 1992) and more malleable linguistic representations (Lev-Ari, 2017) which could speed up rates of change. Further, it has been suggested that the rate of language change may be accelerated by serial founder effects as new languages are started from relative small populations (Atkinson et al., 2008), which could increase the rate of loss of language elements from the ancestral language (Trudgill, 2004; Atkinson, 2011). Small speaker populations may also be more influenced by language contact through trade and marriage across groups, which might increase rates of language change (Bowern, 2010).

In contrast, other studies have found little or no significant effect of population size on the rate of language change or phoneme inventory size (Wichmann and Holman, 2009; Moran et al., 2012). If languages evolve in a purely stochastic manner, analogous to neutral molecular evolution, then rates of change might be independent of population size (Neiman, 1995; Shennan and Wilkinson, 2001; Bentley et al., 2004). The controversial claim that the average rate of word turnover is essentially the same in all languages, has led to much-disputed attempts to date language diversification by assuming a uniform rate of change over time (for examples of contributions to this debate see: Swadesh, 1952, 1955; Hoijer, 1956; Rea, 1958; Bergsland and Vogt, 1962; Sankoff, 1970; Blust, 2000). A similar effect has been suggested for cultural evolution because, for a variety of cultural traits from Neolithic pottery motifs to modern American pop songs, the frequency of variants matches the predictions of a purely stochastic model such that the rate of change is reasonably regular (Bentley et al., 2007).

So, despite many studies on a wide range of languages and language features, there is no consensus on whether population size has a consistent influence on patterns and rates of linguistic evolution (Bowern, 2010; Greenhill, 2014). The lack of a consistently predictable influence of population size on language change might indicate that it is not a universally important factor in rates of language change. Alternatively, the inconsistent patterns might also be due to complicated patterns of change. For example, if rates of word gain show different relationships with population size than rates of word loss, then overall rates of change may show no consistent pattern, and the patterns uncovered in any study might depend on the mode of measuring language change (Bromham et al., 2015a). The diversity of conclusions in published studies could also arise from the diversity of languages studied, data types analyzed, or methodological approaches.

Testing these hypotheses has been challenging for several reasons. Most studies analyzing rates of language change have focused on features within one language (e.g., Johnson, 1976), or relied on simulations (e.g., Nettle, 1999), making it difficult to draw general conclusions about language change. Comparative studies of language change also need a way of overcoming the problem of statistical non-independence due to relatedness. Since languages evolve and diversify from shared ancestors, closely related languages are likely to be more similar to each other in many ways. This similarity by descent means that any association between the two traits might simply be due to the co-occurrence of the traits in a common ancestor, even if there is no functional connection between the two. Therefore, statistical tests cannot treat each language as an independent piece of evidence about the relationship between population size and the patterns of language evolution. This methodological problem, often referred to as Galton's problem, can confound attempts to find relationships between language and demographic factors (Moran et al., 2012; Roberts and Winters, 2013).

Our aim in this paper is to examine the influence of one aspect of demography (size of speaker population) on one aspect of language evolution (the gain and loss of words from basic vocabulary). Specifically, we wish to test whether the association between population size and rates of word gain and loss noted in a study of 10 pairs of Polynesian languages reflects a general pattern. The study of Polynesian languages compared the gain and loss of cognate terms for basic vocabulary and demonstrated greater rates of word gain in larger populations and greater rates of word loss in smaller populations (Bromham et al., 2015a). In many ways, Polynesia represents a perfect "laboratory" of language evolution, with a recent, well-characterized history of colonization of previously uninhabited islands (Goodenough, 1957). Most Polynesian languages are restricted to clearly-defined groups of islands, and the population size of speakers is closely correlated with the area inhabited (Bromham et al., 2015a). As they are the product of a recent human expansion (Spriggs, 2010), Polynesian cultures, and languages share many similarities (Pawley, 1967) and are largely found in similar environments (Kirch and Green, 1987). While these features make Polynesia an ideal case study in language evolution, it also makes it difficult to extrapolate from the patterns observed in Polynesia to general patterns of language evolution. Do languages spoken in other parts of the world by much larger groups of people with wider continental distributions show similar patterns?

To test the generality of the relationship between population size and rates of word gain and loss, we chose 153 pairs of closely related sister languages from three of the largest language families, Austronesian, Indo-European, and Niger-Congo (Bantu subfamily). The languages in our analysis are from a wide 
geographic area, from the North Atlantic to the South Pacific (Figure 1). These language pairs span a huge range of speaker population sizes, from Perai to Aputai spoken on the island of Wetar in the Maluku province of Indonesia (spoken by 280 and 150 people, respectively), to Sambaa and Bondei spoken in the mountain regions of Northern Tanzania (664,000 and 50,000 people), to German and Luxembourgish in continental Europe (spoken by $69,800,000^{1}$ and 266,000 people respectively). For each of these families, we used published linguistic databases of basic vocabulary to evaluate relative rates of word gain and loss, using a technique that explicitly accounts for non-independence due to the relatedness of the languages.

\section{MATERIALS AND METHODS}

\section{Language Families}

We analyzed data from three of the largest language families, Austronesian, Indo-European, and Niger-Congo (Bantu subfamily). These language groups span a large range of population sizes, a wide geographic area and varied cultures and histories, which allows us to test the generality of the influence of population size on rates of language change (Figure 1).

The Austronesian language family is the world's second largest, containing 1,274 languages spoken across a wide range of islands as well as on continental landmasses, from Madagascar to Southeast Asia and the Pacific (Hammarström et al., 2016). There are 10 major Austronesian sub-groups, nine of which contain only 20 languages in total, and are spoken by indigenous Formosan people in Taiwan (Blust, 2013). The other languages form the Malayo-Polynesian group, which began diversifying around 4,000 to 4,500 years ago in a series of expansions across the Pacific Ocean (Gray et al., 2009; Hung et al., 2011; Spriggs, 2011; Amano et al., 2013; Ko et al., 2014; Blust, 2015). Austronesian societies include hunter-gatherer groups (e.g., the Mikea in Madagascar), agriculturalists (e.g., the Saisiyat in Taiwan), and complex socially-stratified societies such as in Java or Bali (Geertz, 1959; Jay, 1969). Austronesian languages vary greatly in their range and degree of isolation (Gavin and Sibanda, 2012), from remote Pacific islands containing a single indigenous language, to the diverse larger islands and landmasses of Southeast Asia and Near Oceania where many different languages may come into contact.

The Indo-European language family contains 581 languages in 8-10 sub-families, including many of the languages of Europe (e.g., English, Spanish, Portuguese, Russian), as well as many spoken in the Middle East and India (e.g., Bengali, Farsi, Hindi, Punjabi). The origin of the family is debated: while some place the origin in the Russian Steppes 5,000 years ago (Anthony and Ringe, 2015; Chang et al., 2015; Haak et al., 2015), others date it to Anatolia 8,000 years ago (Renfrew, 1987; Gray and Atkinson, 2003; Gray et al., 2011; Bouckaert et al., 2012). However, the uncertainty concerning the origin of the family does not affect our analysis of closely related sister pairs.

\footnotetext{
${ }^{1}$ The current population of Germany is $\sim 82$ million speakers, but Lewis et al. (2015) cites a 2012 European Commission report for Standard German which indicates 69.8 million native speakers.
}

The Niger-Congo languages comprise the world's largest language family with 1,430 languages spoken across sub-Saharan Africa (Hammarström et al., 2016). The Bantu languages (550 languages), one of the major subgroups of Niger-Congo, are thought to have originated between 4,000 and 5,000 years ago in west central Africa, perhaps near the Nigerian-Cameroon border, and expanded south through the rainforest (Berniell-Lee et al., 2009; Montano et al., 2011; Pakendorf et al., 2011; de Filippo et al., 2012; Currie et al., 2013; Li et al., 2014; Grollemund et al., 2015).

\section{Language Data}

There are many different ways of investigating language change, for example considering changes to lexicon, morphology, phonology, or syntax (Bowern and Evans, 2014). Here we consider one particular form of language evolution, the gain, and loss of word variants from basic vocabulary, as it allows us to make comparable measures of rate of language change across different languages (Bromham et al., 2015a). Basic vocabulary consists of a common set of concepts found in all languages, such as "hand," "mother," or "water," for which the common word forms have been recorded in different languages-sometimes referred to as a Swadesh list (Swadesh, 1955).

We used published databases of the different words (lexemes) used for a defined set of basic concepts (semantic categories). Using curated databases ensures that word forms are recorded in a comparable format for the different languages within a family. Each of the databases identifies cognate sets: forms which exhibit some systematic degree of similarity and are identified as derived from a common ancestor (Durie and Ross, 1996; Bowern and Evans, 2014). For example, the semantic category "tree" is represented by different words in different Indo-European languages. In some languages, the words for "tree or wood" reflect the same homologous cognate class derived from the common proto-Indo-European *deru-o- (Derksen, 2008), including 'ðẹndrọ (Greek), dicricvo (Russian), and English tree (via Old English, trēow). In contrast, the Italic languages have adopted a new lexeme reflected in forms like Latin arbor, French arbre, Italian albero and Spanish árbol. Homologous forms are not just look-alikes but are identified using the linguistic comparative method to determine systematic sound correspondences and phonological innovations (Paul, 1880; Bloomfield, 1933; Durie and Ross, 1996; Bowern and Evans, 2014). We can use these patterns of homology to identify the presence of words shared by descent, the loss of shared cognates from related languages, and also to identify cases of gain of new words that have not been inherited from a common ancestor.

For the Austronesian languages we used the Austronesian Basic Vocabulary Database (ABVD, Greenhill et al., 2008) which contains wordlists for 210 semantic categories from 1,278 languages. For the Indo-European languages, we used the IndoEuropean Lexical Cognacy Database (IELex, Bouckaert et al., 2012), which contains wordlists for 225 semantic categories from 163 languages. Basic vocabulary for 100 words from 409 Bantu languages were provided by Grollemund et al. (2015) in a phylogenetic dataset that records a single variant per semantic category for each language. The wordlists in these three databases are not identical as they have been modified to contain region 


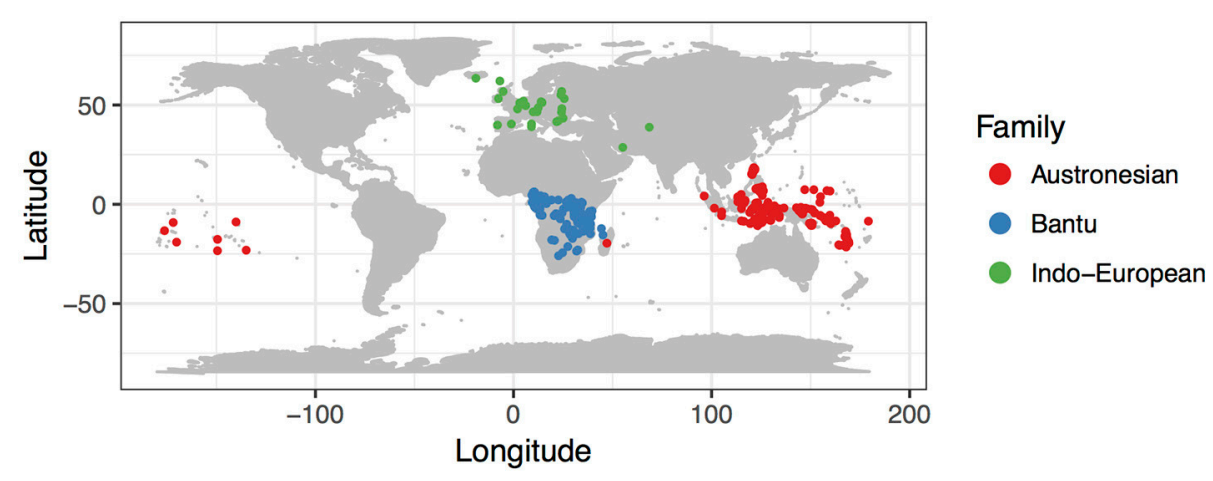

FIGURE 1 | Map of languages included in this study. Each point represents the mid-point of the area occupied by one of the languages included in our study (see Tables 1-3).

specific words, but the lists do overlap substantially as they are based on standard Swadesh lists (Swadesh, 1952).

\section{Language Pairs}

To control for relatedness between languages and avoid Galton's problem, we use a simple and robust method of selecting phylogenetically independent sister pairs. Sister pairs are each other's closest relatives on a phylogeny that form a pair of tips connected by their most recent common ancestor. This means that any difference between the two sister languages has arisen since that last common ancestor, and changes in one language are independent of changes in its sister language. Therefore we can ask questions such as: when two languages evolve from a common stock, does the language with the smaller population acquire new words at a greater or lesser rate than the larger language? If we select sister pairs that are each other's closest relatives, such that they share a more recent common ancestor with each other than either shares with any other language in the analysis, then the pairs are said to be phylogenetically independent (Felsenstein, 1985; Harvey and Pagel, 1991), because any differences between the pair has evolved since their common ancestor, and is not a result of their shared inheritance. Selecting phylogenetically independent sister pairs is like running an experiment over and over again, taking one language, splitting it in two, and seeing which one evolves faster (Bromham, 2016). Given sufficient independent comparisons we can use statistical analysis to look for consistent patterns between the features of languages and their rate of change, by comparing them to their sister languages.

The sister pairs approach has advantages over whole tree phylogenetic methods that use every branch in a phylogeny as a datapoint in an analysis. Using only the tips of the phylogeny avoids the need to infer ancestral states at increasing depths down the phylogeny in order to correlate past states with rates of change inferred from the internal branches of the tree. Using only tip branches also avoids the problem of non-independence between ancestor and descendant lineages within the phylogeny, as each branch is likely to be more similar in many traits to its immediate neighbors than it is to other more distantly related branches.

Phylogenetically independent pairs of languages were chosen from published phylogenies and checked for consistency with language taxonomy based on linguistic comparative data. We did not include creoles as they are hybrid languages with a high degree of borrowing and may have different patterns of change to other related languages (Thomason and Kaufman, 1988; Blasi et al., 2017). We did not include extinct or ancient languages, as their lexical documentation may not be as complete as for extant languages, and their speaker population sizes may also be less well established. We included only well-attested sister pairs in our analysis. We began by selecting sister pairs from the published phylogenies (Gray et al., 2009; Bouckaert et al., 2012; Grollemund et al., 2015; Hammarström et al., 2016), then checked the relationship between pairs in the Ethnologue (Lewis et al., 2015). We discarded any pairs where the classification in the Ethnologue was at odds with pairs identified from the phylogeny. We also used phylogenetic support measures from published phylogenies as a guide to selecting well-attested sister pairs, rejecting any pairs with less than $80 \%$ posterior probability in the published phylogeny.

Contemporary speaker population size was obtained from the Ethnologue (Lewis et al., 2015) using the in area speaker population where given, rather than the total global number of speakers. Languages with insufficient linguistic, temporal or population data were excluded. Thus, this is not an exhaustive list of all sister languages for these language families, but a conservative selection which fits all relevant criteria for this study. This selection process resulted in 81 pairs of Austronesian languages (Table 1), 14 pairs of Indo-European languages (Table 2), and 58 pairs of Bantu languages (Table 3 ).

Language pairs that have a shorter period of divergence will have larger uncertainty in the estimates of their rates of language change (Welch and Waxman, 2008; Hua et al., 2015), so we use estimated branch lengths between sister languages to correct for this effect. We extracted branch lengths from the published language phylogenies (Gray et al., 2009; Bouckaert et al., 2012; Grollemund et al., 2015) which are estimated using phylogenetic dating methods from their total datasets combined with historical 
TABLE 1 | Sister pairs of languages from the Austronesian language family, showing the taxon label, the ISO-639-3 language identification code, the number of gains, losses, and total changes, population size, and branch-length.

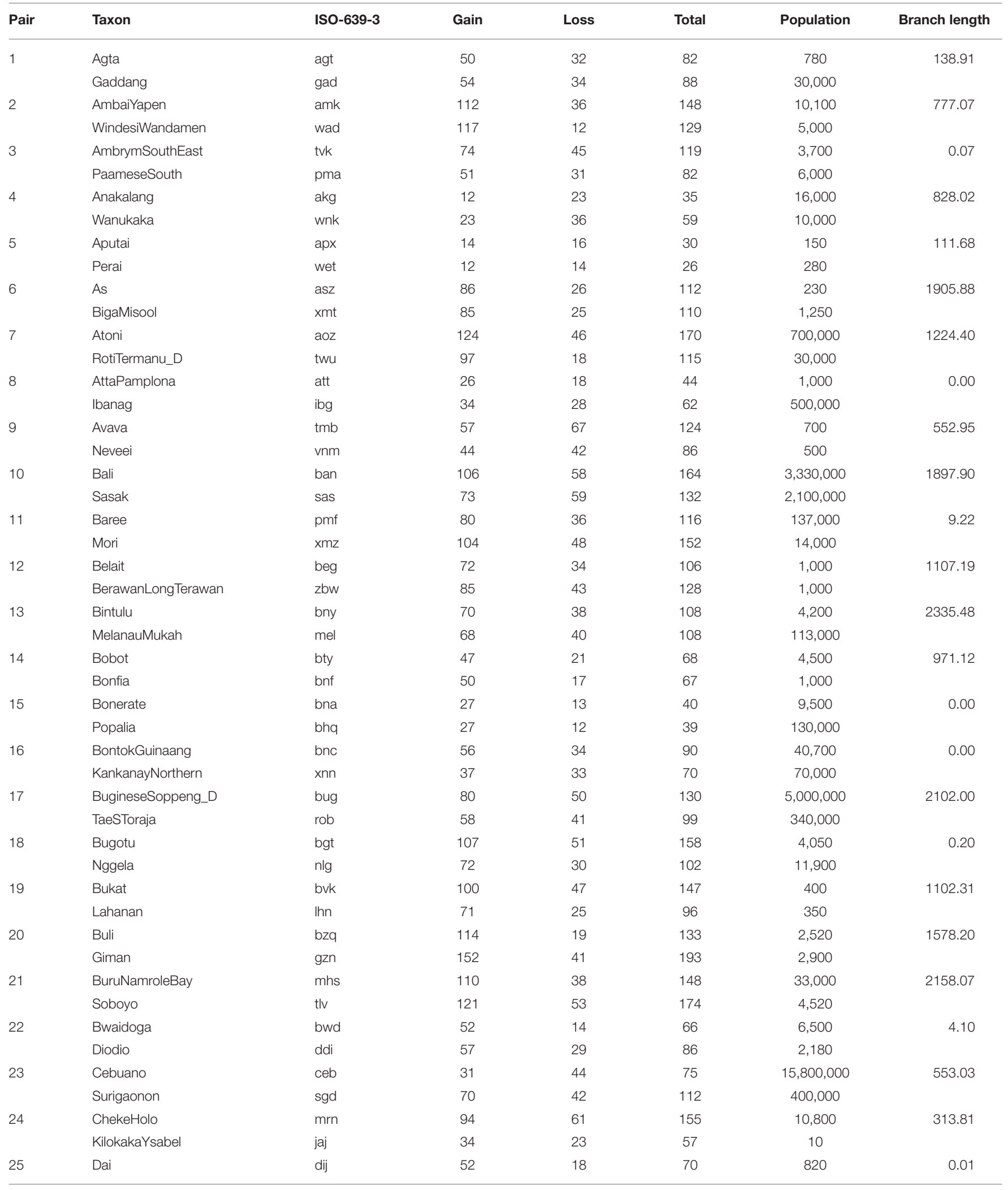


TABLE 1 | Continued

\begin{tabular}{|c|c|c|c|c|c|c|c|}
\hline Pair & Taxon & ISO-639-3 & Gain & Loss & Total & Population & Branch length \\
\hline & NorthBabar & bcd & 50 & 17 & 67 & 1,000 & \\
\hline \multirow[t]{2}{*}{26} & Dehu & dhv & 190 & 22 & 212 & 13,000 & 1722.11 \\
\hline & Nengone & nen & 185 & 30 & 215 & 8,720 & \\
\hline \multirow[t]{2}{*}{27} & Dobuan & dob & 73 & 38 & 111 & 10,000 & 667.39 \\
\hline & Molima & $\operatorname{mox}$ & 81 & 35 & 116 & 4,010 & \\
\hline \multirow[t]{2}{*}{29} & Gapapaiwa & pwg & 76 & 18 & 94 & 3,000 & 756.15 \\
\hline & Ubir & ubr & 101 & 44 & 145 & 2,560 & \\
\hline \multirow[t]{2}{*}{30} & Geser & ges & 63 & 23 & 86 & 36,500 & 476.20 \\
\hline & Watubela & wah & 71 & 36 & 107 & 4,000 & \\
\hline 31 & GhariGuadalcanal & gri & 39 & 31 & 70 & 12,100 & 0.01 \\
\hline \multirow[t]{2}{*}{33} & HituAmbon & htu & 64 & 27 & 91 & 16,000 & 531.14 \\
\hline & Paulohi & plh & 73 & 33 & 106 & 50 & \\
\hline \multirow[t]{2}{*}{34} & HoavaNewGeorgia & hoa & 61 & 41 & 102 & 460 & 400.12 \\
\hline & MarovoNewGeorgia & mvo & 67 & 54 & 121 & 8,090 & \\
\hline \multirow[t]{2}{*}{35} & Imroing & $\mathrm{imr}$ & 31 & 24 & 55 & 560 & 327.51 \\
\hline & TelaMasbuar & tvm & 25 & 16 & 41 & 1,050 & \\
\hline \multirow[t]{2}{*}{36} & Inibaloi & ibl & 35 & 33 & 68 & 111,000 & 117.06 \\
\hline & KallahanKayapaProper & kak & 22 & 20 & 42 & 15,000 & \\
\hline \multirow[t]{2}{*}{37} & ItnegBinongan & itb & 34 & 40 & 74 & 7,500 & 0.01 \\
\hline & KalingaGuinaangLubuagan_D & knb & 29 & 36 & 65 & 30,000 & \\
\hline 38 & Jawe & jaz & 109 & 24 & 133 & 990 & 0.00 \\
\hline \multirow[t]{2}{*}{42} & Kedang & ksx & 106 & 37 & 143 & 30,000 & 1219.42 \\
\hline & Lamaholot & slp & 93 & 33 & 126 & 180,000 & \\
\hline \multirow[t]{2}{*}{43} & Kemak & kem & 65 & 16 & 81 & 72,000 & 866.01 \\
\hline & Mambai & mgm & 80 & 27 & 107 & 131,000 & \\
\hline \multirow[t]{2}{*}{44} & Kerinci & $\mathrm{kvr}$ & 56 & 33 & 89 & 260,000 & 188.09 \\
\hline & Minangkabau & $\min$ & 29 & 37 & 66 & $5,530,000$ & \\
\hline 45 & Komering & $\mathrm{kge}$ & 74 & 37 & 111 & 470,000 & 1899.99 \\
\hline & Lampung & ljp & 45 & 29 & 74 & 827,000 & \\
\hline 46 & KoronadalBlaan & bpr & 10 & 11 & 21 & 150,000 & 415.53 \\
\hline & SaranganiBlaan & bps & 4 & 5 & 9 & 90,800 & \\
\hline 47 & Kuanua & ksd & 111 & 31 & 142 & 61,000 & 652.24 \\
\hline & LungaLungaMinigir & vmg & 83 & 21 & 104 & 600 & \\
\hline 48 & KwaraaeSolomonlslands & kwf & 43 & 33 & 76 & 32,400 & 197.90 \\
\hline & Toambaita & mlu & 47 & 49 & 96 & 12,600 & \\
\hline 49 & Leipon & lek & 42 & 22 & 64 & 650 & 840.70 \\
\hline & Loniu & los & 43 & 20 & 63 & 460 & \\
\hline 50 & Lenakel & tnl & 34 & 25 & 59 & 11,500 & 0.00 \\
\hline & TannaSouthwest & nwi & 26 & 13 & 39 & 4,500 & \\
\hline
\end{tabular}


TABLE 1 | Continued

\begin{tabular}{|c|c|c|c|c|c|c|c|}
\hline Pair & Taxon & ISO-639-3 & Gain & Loss & Total & Population & Branch length \\
\hline \multirow[t]{2}{*}{51} & Levei & $\mathrm{t} \mid \mathrm{x}$ & 62 & 16 & 78 & 1,600 & 1480.51 \\
\hline & Likum & lib & 56 & 13 & 69 & 80 & \\
\hline \multirow[t]{2}{*}{52} & Lou & loj & 74 & 36 & 110 & 1,000 & 2.12 \\
\hline & Nauna & nen & 64 & 25 & 89 & 100 & \\
\hline 53 & Luangiua & ojv & 6 & 14 & 20 & 2,370 & 189.54 \\
\hline 54 & MerinaMalagasy & plt & 119 & 54 & 173 & $7,520,000$ & \\
\hline \multirow[t]{2}{*}{55} & Manam & mva & 94 & 36 & 130 & 7,950 & 171.10 \\
\hline & Wogeo & woc & 87 & 34 & 121 & 1,620 & \\
\hline \multirow[t]{2}{*}{56} & Mangareva & $\mathrm{mrv}$ & 1 & 28 & 29 & 600 & 670.85 \\
\hline & Marquesan & mrq & 23 & 33 & 56 & 5,400 & \\
\hline 58 & ManoboSaranganiKayaponga_D & $\mathrm{mbs}$ & 33 & 34 & 67 & 58,000 & \\
\hline \multirow[t]{2}{*}{59} & Masiwang & bnf & 17 & 4 & 21 & 1,000 & 0.00 \\
\hline & Werinama & bty & 19 & 7 & 26 & 4,500 & \\
\hline \multirow[t]{2}{*}{60} & Matukar & mjk & 51 & 16 & 67 & 430 & 556.52 \\
\hline & Megiar & tbc & 49 & 18 & 67 & 40,000 & \\
\hline \multirow[t]{2}{*}{61} & Modang & $m \times d$ & 90 & 24 & 114 & 15,300 & 339.52 \\
\hline & PunanKelai & sge & 83 & 21 & 104 & 2,000 & \\
\hline \multirow[t]{2}{*}{62} & Mokilese & $\mathrm{mkj}$ & 15 & 9 & 24 & 1,500 & 1232.98 \\
\hline & Ponapean & pon & 34 & 29 & 63 & 31,350 & \\
\hline \multirow[t]{2}{*}{63} & Mortlockese & $\mathrm{mrl}$ & 2 & 6 & 8 & 5,900 & 156.44 \\
\hline & Satawalese & stw & 1 & 7 & 8 & 460 & \\
\hline \multirow[t]{2}{*}{67} & NgaiborSAru & txn & 100 & 19 & 119 & 7,910 & 1319.07 \\
\hline & UjirNAru & udj & 89 & 8 & 97 & 1,030 & \\
\hline \multirow[t]{2}{*}{68} & Nguna & $\| p$ & 57 & 24 & 81 & 9,500 & 2179.01 \\
\hline & SouthEfate & erk & 62 & 39 & 101 & 6,000 & \\
\hline \multirow[t]{2}{*}{69} & Niue & niu & 12 & 52 & 64 & 2,030 & 0.00 \\
\hline & UveaEast & wls & 7 & 25 & 32 & 9,620 & \\
\hline \multirow[t]{2}{*}{70} & PeteraraMaewo & mwo & 45 & 44 & 89 & 1,400 & 1667.29 \\
\hline & Raga & Iml & 47 & 38 & 85 & 6,500 & \\
\hline 71 & Rurutuan & aut & 38 & 19 & 57 & 3,000 & 31.67 \\
\hline & TahitianModern & $\operatorname{tah}$ & 27 & 33 & 60 & 68,260 & \\
\hline 72 & Saliba & sbe & 82 & 29 & 111 & 2,500 & 0.00 \\
\hline & Suau & swp & 48 & 24 & 72 & 6,800 & \\
\hline 73 & SangilSaraganilslands & snl & 42 & 41 & 83 & 15,000 & 497.32 \\
\hline & SangirTabukang_D & sxn & 20 & 19 & 39 & 255,000 & \\
\hline 74 & Seimat & ssg & 98 & 39 & 137 & 1,000 & 2128.97 \\
\hline & Wuvulu & wuv & 100 & 35 & 135 & 1,000 & \\
\hline 75 & Serili & sve & 27 & 14 & 41 & 330 & 480.25 \\
\hline & SouthEastBabar & $v b b$ & 21 & 10 & 31 & 4,460 & \\
\hline
\end{tabular}


TABLE 1 | Continued

\begin{tabular}{|c|c|c|c|c|c|c|c|}
\hline Pair & Taxon & ISO-639-3 & Gain & Loss & Total & Population & Branch length \\
\hline \multirow[t]{2}{*}{76} & SubanonSiocon & suc & 47 & 17 & 64 & 125,000 & 415.21 \\
\hline & SubanunSindangan & syb & 50 & 23 & 73 & 140,000 & \\
\hline 77 & Ura & uur & 61 & 28 & 89 & 6 & \\
\hline 78 & Taiof & sps & 88 & 39 & 127 & 1,400 & 26.49 \\
\hline 79 & TungagTungakLavongai & $\mathrm{Icm}$ & 123 & 22 & 145 & 12,000 & \\
\hline \multirow[t]{2}{*}{80} & Tokelau & $\mathrm{tkl}$ & 12 & 45 & 57 & 1,410 & 1428.51 \\
\hline & Tuvalu & tvl & 4 & 21 & 25 & 10,700 & \\
\hline \multirow[t]{2}{*}{81} & VaghuaChoiseul & tva & 63 & 35 & 98 & 1,960 & 0.01 \\
\hline & Varisi & vrs & 40 & 20 & 60 & 5,160 & \\
\hline
\end{tabular}

and archeological information (Tables 1, 3). Because the relative height of the ancestral node of any given pair will be determined not only by the differences between the pair but also by rates of change estimated on the rest of the phylogeny, it should be at least partially independent of the number of gains and losses between members of any given pair. Branch lengths were only used for the Welch \& Waxman analysis (see below).

\section{Comparing Rates of Language Change}

We use comparisons of words from basic vocabulary between pairs of closely-related languages to identify instances of gain and loss of words. We identified patterns of word gain and loss by recording instances where a cognate form within a given semantic category was present in one language in a sister pair but not found in its sister language (Bromham et al., 2015a). A cognate class is a set of words identified as derived from a common ancestor, and therefore the presence of a cognate class in one language of a pair, and in other languages within the family, implies the presence of that cognate class in the common ancestral language of the pair. This method differs from approaches where the net dissimilarity between lists of terms is compared (Wichmann and Holman, 2009). Instead we use only those words that show a pattern of occurrence that is informative for determining differences in rates of gain and loss of words (Bromham et al., 2015a).

If a word form found in one sister language has a cognate in other languages in the language family, then it is likely to have been inherited from the common ancestor. This implies that the absence of that cognate form in the other sister language must be due to its loss after divergence from the common ancestor of the pair (Figure 2). If one of the sister languages has a unique word form that has no recognized cognates in any other language in the family, then it presumably represents a gain of a new word since it split from its sister language. Therefore we can identify instances of word gain and loss in both members of a related pair of languages. Any such changes that have occurred in one sister pair of languages can be considered to have happened independently from changes in other sister pair of languages, so these comparisons can be treated as statistically independent data points (Bromham et al., 2015a).

Our analysis only includes cognate classes showing ratesinformative patterns that allow us to localize a word gain or loss to only one member of a sister pair (Figure 2). There are two rates-informative patterns. Presence of a cognate class in one member of the pair but not the other indicates a loss of the shared ancestral cognate form from one sister language after divergence from the common ancestor. Presence of a novel form in one member of the pair that has no known cognates in any other member of the language family indicates the gain of a new word in one sister language after divergence from the common ancestor. We did not consider cognate forms that are present in both members of a sister pair because they have both inherited those forms from their common ancestor, and neither has lost that cognate, so those cognates are non-informative for rates of gain and loss. Similarly, we did not count any cognate class that is absent from both members of a sister pair, on the assumption that it was not present in their common ancestor.

We do not include any identified loan words in the analysis, so any cognate terms shared by two languages should be present in the language due to inheritance from a common ancestor, rather than borrowing (horizontal transfer) from another language. The addition of a new word does not necessarily involve the loss of an existing word as languages can have multiple lexemes for one category, therefore each recorded gain, or loss of a lexeme was counted as a separate event, regardless of semantic category. Any lexemes that were recorded as "doubtful" or "exclude" in the databases were excluded from our analysis. Any semantic categories that did not contain entries for both languages in the pair were also excluded as we are unable to ascertain if this absence is a true absence or simply missing data.

This counting procedure will in some cases count semantic shifts as a change (e.g., Danish trce "tree" is cognate with protoIndo-European * dóru but has shifted to also mean "wood"). Due to the nature of these datasets (cognate classes coded within a limited number of semantic categories), we cannot quantify semantic shift, which may include gain, or loss of meaning from unrecorded semantic categories. Cognates that change 
TABLE 2 | Sister pairs of languages from the Indo-European language family, showing the taxon label, the ISO-639-3 language identification code, the number of gains, losses, and total changes, population size, and branch-length.

\begin{tabular}{|c|c|c|c|c|c|c|c|}
\hline Pair & Taxon & ISO-639-3 & Gain & Loss & Total & Population & Branch length \\
\hline \multirow[t]{2}{*}{1} & Persian_List & pes & 16 & 36 & 52 & $45,000,000$ & 788.52 \\
\hline & Tadzik & $\operatorname{tgk}$ & 39 & 26 & 65 & $6,380,000$ & \\
\hline \multirow[t]{2}{*}{2} & Romanian_List & ron & 41 & 19 & 60 & $19,900,000$ & 727.95 \\
\hline & Vlach & rup & 31 & 44 & 75 & 50,000 & \\
\hline \multirow[t]{2}{*}{3} & Sardinian_C & sro & 12 & 22 & 34 & 500,000 & 615.19 \\
\hline & Sardinian_N & src & 20 & 29 & 49 & 500,000 & \\
\hline \multirow[t]{2}{*}{4} & Ladin & $\| d$ & 13 & 18 & 31 & 31,000 & 649.30 \\
\hline & Romansh & roh & 20 & 33 & 53 & 40,000 & \\
\hline \multirow[t]{2}{*}{5} & French & fra & 2 & 11 & 13 & $60,000,000$ & 522.68 \\
\hline & Walloon & wln & 20 & 26 & 46 & 600,000 & \\
\hline \multirow[t]{2}{*}{6} & Portuguese_ST & por & 36 & 24 & 60 & $10,000,000$ & 337.65 \\
\hline & Spanish & spa & 19 & 36 & 55 & $38,400,000$ & \\
\hline \multirow[t]{2}{*}{7} & Irish_A & gle & 40 & 25 & 65 & 138,000 & 563.10 \\
\hline & Scots_Gaelic & gla & 47 & 25 & 72 & 58,700 & \\
\hline \multirow[t]{2}{*}{8} & Dutch_List & nld & 7 & 17 & 24 & $15,700,000$ & 208.55 \\
\hline & Flemish & vls & 5 & 22 & 27 & $1,070,000$ & \\
\hline \multirow[t]{2}{*}{9} & German_ST & deu & 7 & 14 & 21 & $69,800,000$ & 641.05 \\
\hline & Luxembourgish & Itz & 17 & 30 & 47 & 266,000 & \\
\hline \multirow[t]{2}{*}{10} & Faroese & fao & 9 & 14 & 23 & 66,000 & 777.56 \\
\hline & Icelandic_ST & isl & 7 & 27 & 34 & 230,000 & \\
\hline \multirow[t]{2}{*}{11} & Bulgarian & bul & 19 & 44 & 63 & $7,020,000$ & 712.58 \\
\hline & Macedonian & $\mathrm{mkd}$ & 32 & 14 & 46 & $1,340,000$ & \\
\hline \multirow[t]{2}{*}{12} & Lusatian_L & dsb & 4 & 8 & 12 & 6,670 & 54.80 \\
\hline & Lusatian_U & hsb & 1 & 5 & 6 & 13,300 & \\
\hline \multirow[t]{2}{*}{13} & Byelorussian & bel & 15 & 45 & 60 & $2,220,000$ & 535.34 \\
\hline & Ukrainian & ukr & 42 & 26 & 68 & $32,000,000$ & \\
\hline \multirow[t]{2}{*}{14} & Latvian & lav & 68 & 46 & 114 & $1,470,000$ & 1359.36 \\
\hline & Lithuanian_ST & lit & 61 & 40 & 101 & $2,800,000$ & \\
\hline
\end{tabular}

meaning and undergo semantic shifts into a new category in the word list might appear as the gain of a new cognate into the recipient semantic category. If there is a subsequent change of meaning away from the original semantic category, then we would count this as loss of a cognate from the original semantic category. While this represents a somewhat different kind of change from the origin, replacement and loss of lexical items, it is still indicative of language change. In this way, we may include changes in both form and meaning. One of the ways that the population size hypothesis might affect language change is through altering semantics.

The total number of gains, losses, and non-informative results were counted for all available semantic categories for each pair of languages. The raw counts were standardized by the total number of comparisons made between the pairs (gains + losses + non informative + excluded) to allow for comparisons to be made between languages. We have developed a Python package, RateCounter (https://github.com/SimonGreenhill/RateCounter), to extract this rate information from common phylogenetic file formats.

\section{Statistical Analysis}

We applied two statistical analyses to test for any consistent relationship between population size and rates of word gain and loss. One analysis is Poisson regression (Bromham et al., 2015b;
Hua et al., 2015), which assumes that gain and loss counts follow a Poisson process, and rates of word gain and loss are linear functions of population size on a log-log scale (which confines rates to positive values). The regression coefficient between population size and rate of word gain and loss was estimated by accounting for the phylogenetic structure of the data and using a model with stable population size, origination of new language by fission, and negligible founder effect-the simplest population model tests from a previous study (Bromham et al., 2015a). We also tested an alternative model that incorporates population growth, to reflect recent population expansion, however this model provided a poor fit to the data and would not converge for most datasets. Therefore we applied the simplest model because it has the least number of parameters and assumptions and does not require divergence dates. To assess the model fit, we used likelihood ratio tests to compare each model to null models which assume no effect of population size on rates of language evolution. The effect size was calculated as the pseudo $R^{2}$ measures for the Poisson regression (Table $\mathbf{1}$ ).

In addition, we performed an analysis that first uses the Welch \& Waxman test to remove pairs where the divergence between the sister languages is too recent to obtain reliable measures of rates of word gain and loss (Welch and Waxman, 2008). This is done by progressively removing pairs until there is no negative relationship between the absolute value of the standardized difference in the counts of gains and losses between sister languages and the square root of divergence time (Welch and Waxman, 2008), here represented by branch length from the published phylogeny (Tables 1-3). This analysis asks whether the difference in population size between each pair predicts the difference in the gain and loss rate, while accounting for the differences in divergence times between the pairs. So the difference in the gain and loss rate needs to be standardized by divergence times. Since the quantity of data for each language pair may vary, we also need to standardize the differences in the gain and loss rate by the amount of available data. We calculate the standardized difference as the difference in the counts of gains and losses between sister languages divided by their average counts of gains and losses and by the square root of branch length (following Bromham et al., 2015a). We removed any pairs for which the standardized difference was not a reliable estimate of difference in gains or losses rate, for example due to too recent a divergence or insufficient differences between the languages. following the procedure of Welch and Waxman (2008). After removing pairs with unreliable estimates, the analysis then applies least squares regression of the standardized differences between the remaining sister language pairs against their differences in log-transformed population sizes divided by the square root of branch length (Bromham et al., 2015a).

\section{RESULTS}

The Poisson regression of population size and rates of change in the Indo-European language family (14 pairs) suggests that languages with smaller speaker population sizes had significantly 
TABLE 3 | Sister pairs of languages from the Bantu language sub-family, showing the taxon label, the ISO-639-3 language identification code, the number of gains, losses, and total changes, population size, and branch-length.

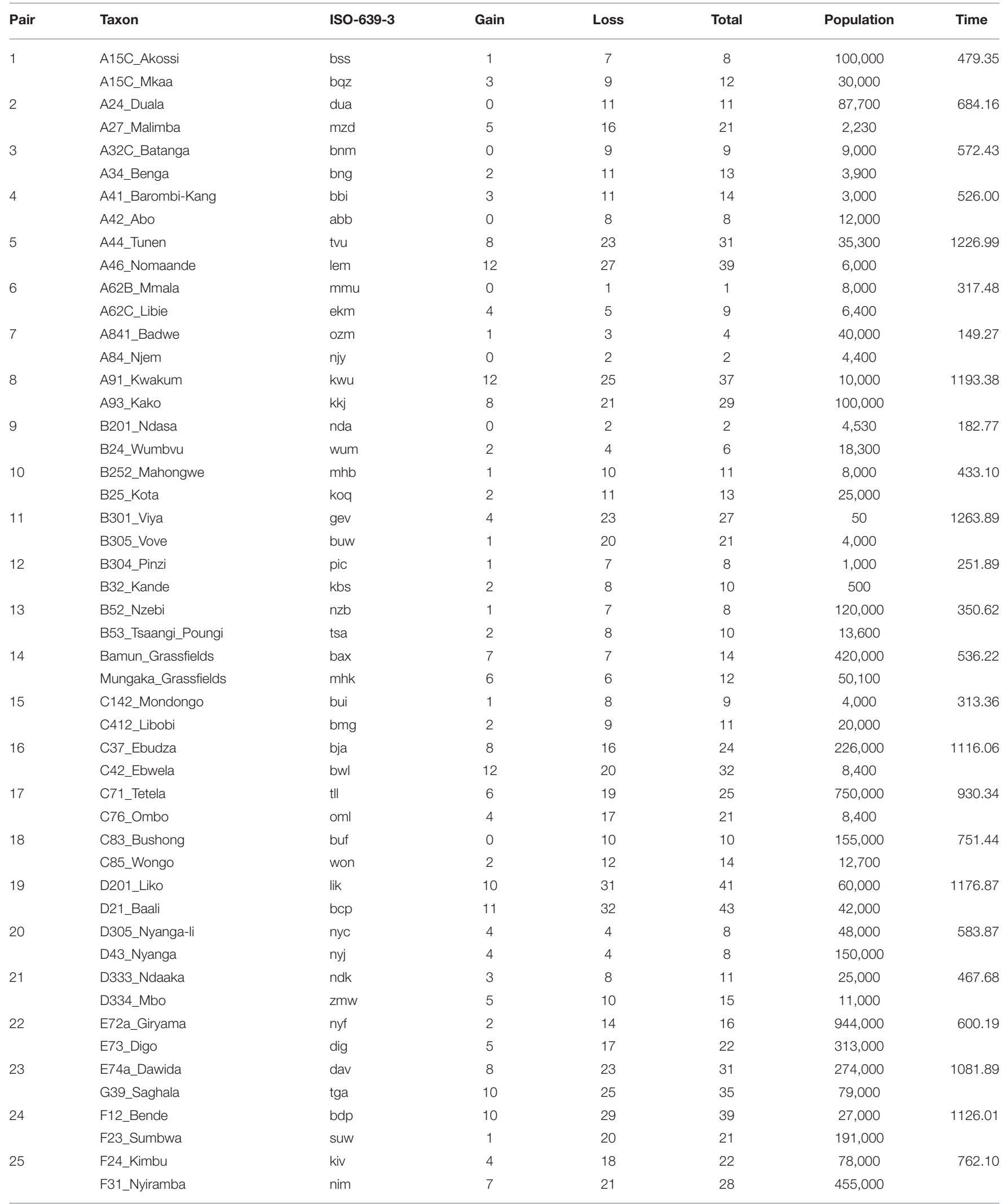


TABLE 3 | Continued

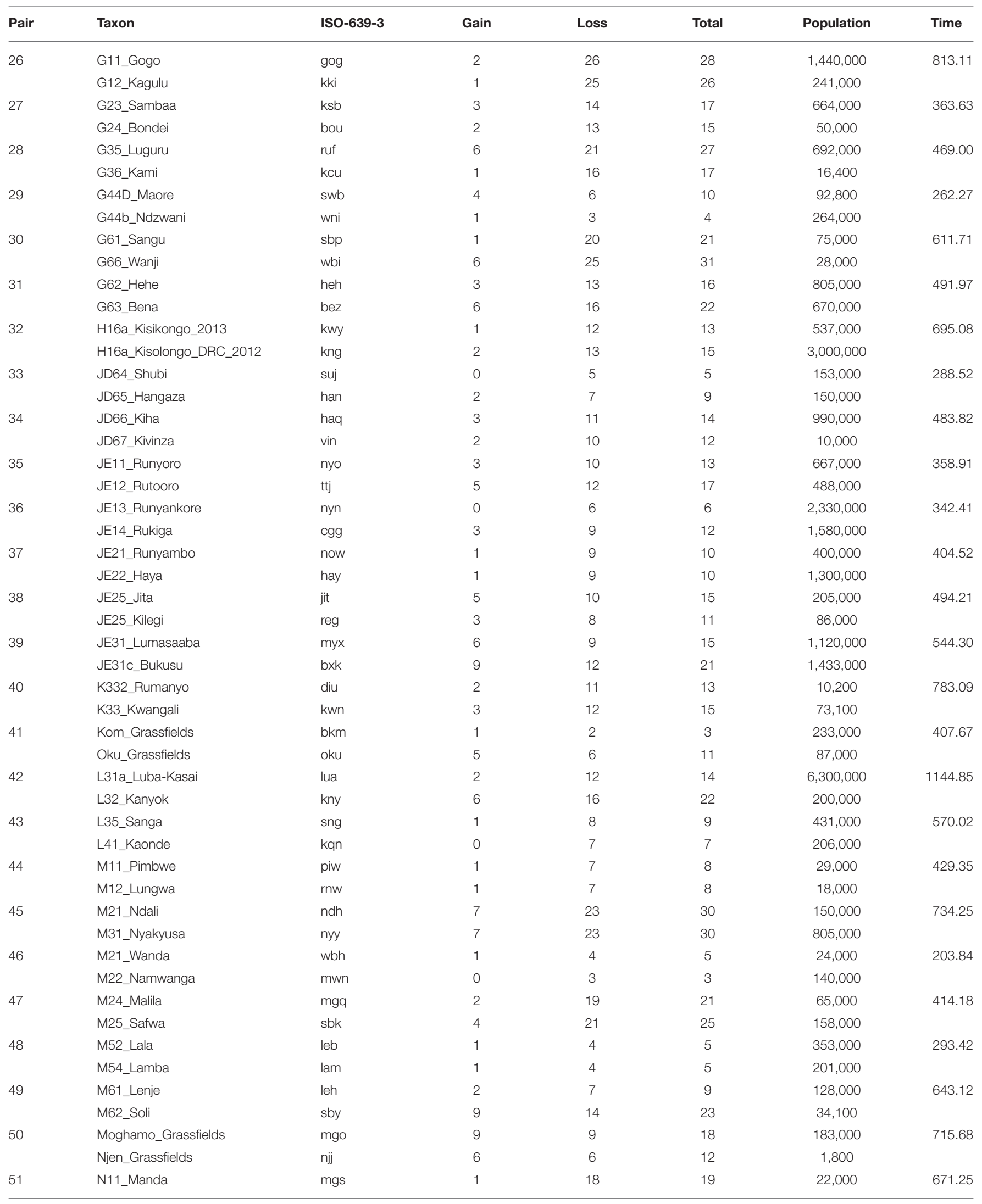


TABLE 3 | Continued

\begin{tabular}{|c|c|c|c|c|c|c|c|}
\hline Pair & Taxon & ISO-639-3 & Gain & Loss & Total & Population & Time \\
\hline & N12_Ngoni & ngo & 3 & 20 & 23 & 170,000 & \\
\hline 52 & N13_Matengo & mgv & 5 & 16 & 21 & 150,000 & 545.66 \\
\hline \multirow[t]{2}{*}{53} & N31_Chewa & nya & 6 & 18 & 24 & $7,000,000$ & 755.02 \\
\hline & N42_Kunda & kdn & 1 & 13 & 14 & 145,000 & \\
\hline \multirow[t]{2}{*}{55} & P31G_kkorovere & mgh & 6 & 6 & 12 & 963,000 & 390.78 \\
\hline & P31_Emakhua & vmw & 2 & 2 & 4 & $3,090,000$ & \\
\hline \multirow[t]{2}{*}{56} & S11_Shona & sna & 4 & 13 & 17 & $10,700,000$ & 858.44 \\
\hline & S16_Kalanga & kck & 6 & 15 & 21 & 700,000 & \\
\hline 57 & S311_Shekgalagari & $\mathrm{xkv}$ & 8 & 14 & 22 & 40,000 & 557.18 \\
\hline
\end{tabular}

Language identification codes following Guthrie's scheme are prepended to the taxon label.

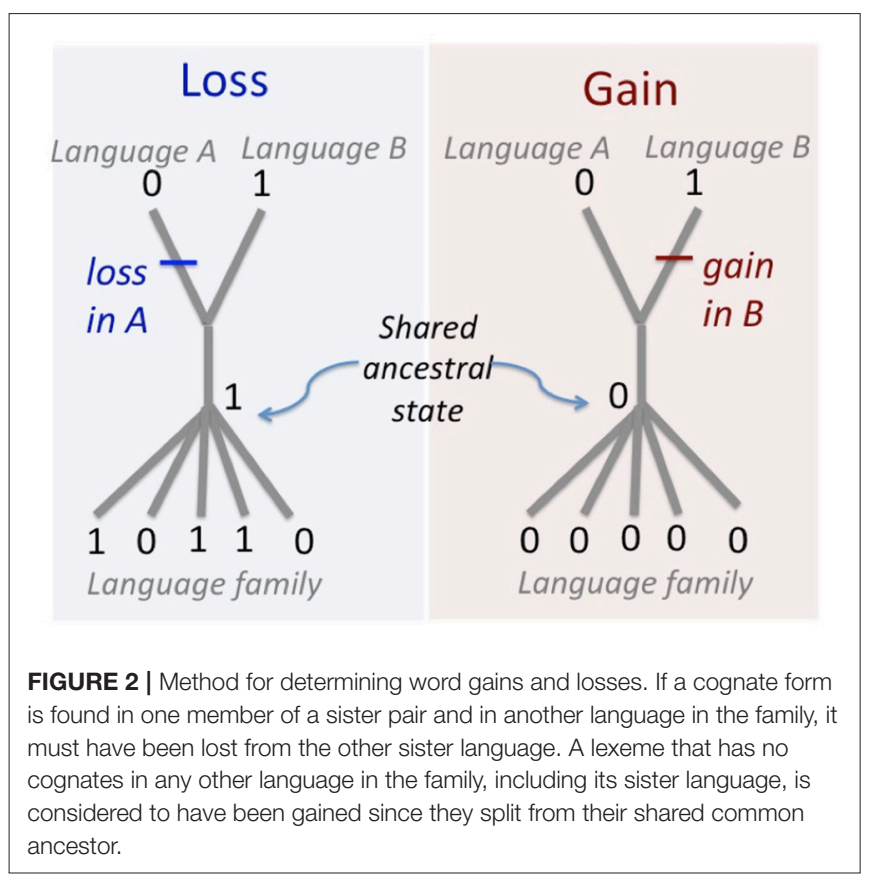

higher rates of word loss (Table 4, Figure 3). Least squares regression also suggests a significant negative relationship between contrasts in population size and contrasts in the rate of word loss (coefficient $=-0.13, P=0.05, R^{2}=0.22$ ). However, this result is no longer significant when a single shallow pair, Upper and Lower Sorbian (Lusatian_U and Lusatian_L) are removed following the Welch \& Waxman test (Table 5, Figure 4).

We found no evidence of a significant association between rate of word gain and population size in the Indo-European language pairs, nor in gains or losses for the Austronesian and
TABLE 4 | Results of Poisson regression on Population size and rate of language change in pairs of Austronesian, Indo-European languages, and Bantu languages.

\begin{tabular}{|c|c|c|c|c|c|c|}
\hline & $\mathbf{N}$ & Mean & SE & Statistic & $P$-value & $R^{2}$ \\
\hline \multicolumn{7}{|c|}{ AUSTRONESIAN } \\
\hline Gain & 81 & 0.000 & 0.017 & 0.07 & 0.791 & 0.000 \\
\hline Loss & 81 & 0.001 & 0.024 & 0.13 & 0.718 & 0.001 \\
\hline \multicolumn{7}{|c|}{ INDO-EUROPEAN } \\
\hline Gain & 14 & -0.042 & 0.062 & 2.18 & 0.140 & 0.035 \\
\hline Loss & 14 & -0.095 & 0.058 & 12.82 & 0.000 & 0.216 \\
\hline \multicolumn{7}{|c|}{ BANTU } \\
\hline Gain & 58 & -0.000 & 0.086 & 0.01 & 0.911 & 0.000 \\
\hline Loss & 58 & -0.000 & 0.047 & 0.00 & 0.951 & 0.000 \\
\hline
\end{tabular}

N: number of language pairs; Mean, estimated regression coefficient for the relationship between population size and rates of language change; SE, standard error for the regression coefficient; Statistic, likelihood ratio; $P$-value, results significant at 0.05 shown in bold; $R^{2}$,pseudo $R^{2}$ for Poisson regression.

Bantu data (Tables 4, 5, Figure 4). One possible explanation for the observation of a significant relationship between rate of language change and population size only in the Indo-European languages is that we expect this dataset to have relatively higher power to detect differences in rates of change. Although the IndoEuropean dataset has many fewer pairs than the Austronesian or Bantu datasets, the Indo-European word list contains more cognates per category: that is, there are more synonymous lexemes per word (see Table 6). The test we use to detect rate differences is broadly based on the Tajima test (Tajima, 1993), the power of which is dependent on the number of variable sites, which are columns in DNA alignments in which the sequences being compared differ from each other (Bromham et al., 2000). It may be that the more synonyms recorded per lexical category, the more likely we will record a true gain and less likely we will record a false loss (i.e., a synonym is used less frequently 


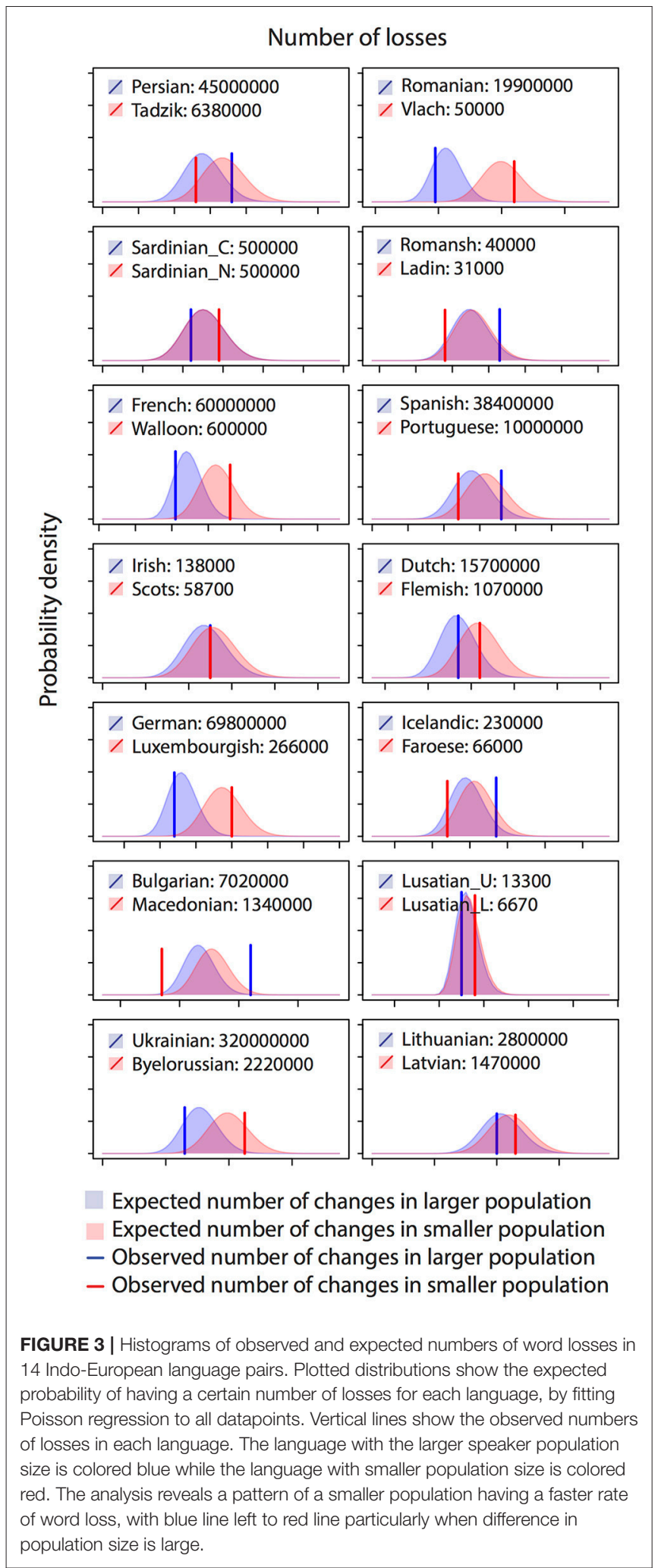

in a language but not completely lost). This may be a particular problem for the Bantu dataset which has the fewest synonyms as it was collected following Swadesh's $(1952,1955)$ approach
TABLE 5 | Results of least squares regression after Welch \& Waxman test on Population size and rate of language change in pairs of Austronesian, Indo-European, and Bantu languages.

\begin{tabular}{|c|c|c|c|c|c|c|}
\hline & $\mathbf{N}$ & Mean & $S E$ & Statistic & $P$-value & $R^{2}$ \\
\hline \multicolumn{7}{|c|}{ AUSTRONESIAN LANGUAGES } \\
\hline Gain & 59 & 0.041 & 0.024 & 3.06 & 0.086 & 0.034 \\
\hline Loss & 59 & 0.032 & 0.021 & 2.31 & 0.135 & 0.022 \\
\hline \multicolumn{7}{|c|}{ INDO-EUROPEAN LANGUAGES } \\
\hline Gain & 13 & -0.047 & 0.073 & 0.42 & 0.532 & -0.051 \\
\hline Loss & 13 & -0.084 & 0.053 & 2.52 & 0.141 & 0.112 \\
\hline \multicolumn{7}{|c|}{ BANTU LANGUAGES } \\
\hline Gain & 47 & -0.027 & 0.074 & 0.13 & 0.718 & -0.019 \\
\hline Loss & 41 & 0.003 & 0.018 & 0.02 & 0.886 & -0.025 \\
\hline
\end{tabular}

$\mathrm{N}$, number of language pairs after removing shallow pairs in regression; Mean, estimated regression coefficient for the relationship between population size and rates of language change; SE, standard error for the regression coefficient; Statistic, F-statistic for least square regression; $P$-value, results are considered significant at 0.05 level; $R^{2}$, adjusted $R^{2}$ for least square regression.

whereby only the most frequent word was entered for each lexical category. This means that cognates may be retained in lineages even if not recorded, if there are in less frequent usage than a more predominant form. A gain, in this case, may represent the rise in frequency of one cognate over alternatives, therefore may not involve the loss of an alternative form. Given the differences in the nature of the recorded data, we do not know whether the lack of significant relationships for the Bantu and Austronesian data is due to lack of a consistent association between population size and rates of word gain and loss in these language groups, or due to biases in counts of word gain and loss and thus insufficient power to detect rate differences for these datasets.

\section{DISCUSSION}

Languages evolve, creating patterns of descent and relatedness reminiscent of biological species. Because of this, tools from evolutionary biology are being increasingly applied to studying language change (Levinson and Gray, 2012; Gavin et al., 2013; Bromham, 2017). However, we cannot assume that the mechanisms underlying change, or the observed patterns and rates of change, will be the same for both languages and biological lineages.

Evolutionary theory makes clear predictions about the relationship between population size and rates and patterns of genetic change. Selection is more efficient in large populations, so deleterious mutations should be removed more effectively, and advantageous mutations should more rapidly go to fixation. However, in smaller populations, random sampling effects can have a comparatively greater impact on the frequency of genetic variants, so that positively selected mutations may be reduced in frequency by chance, and may thus occasionally be lost rather than going to fixation. Conversely, in small populations, slightly deleterious changes may increase in frequency by chance, and 


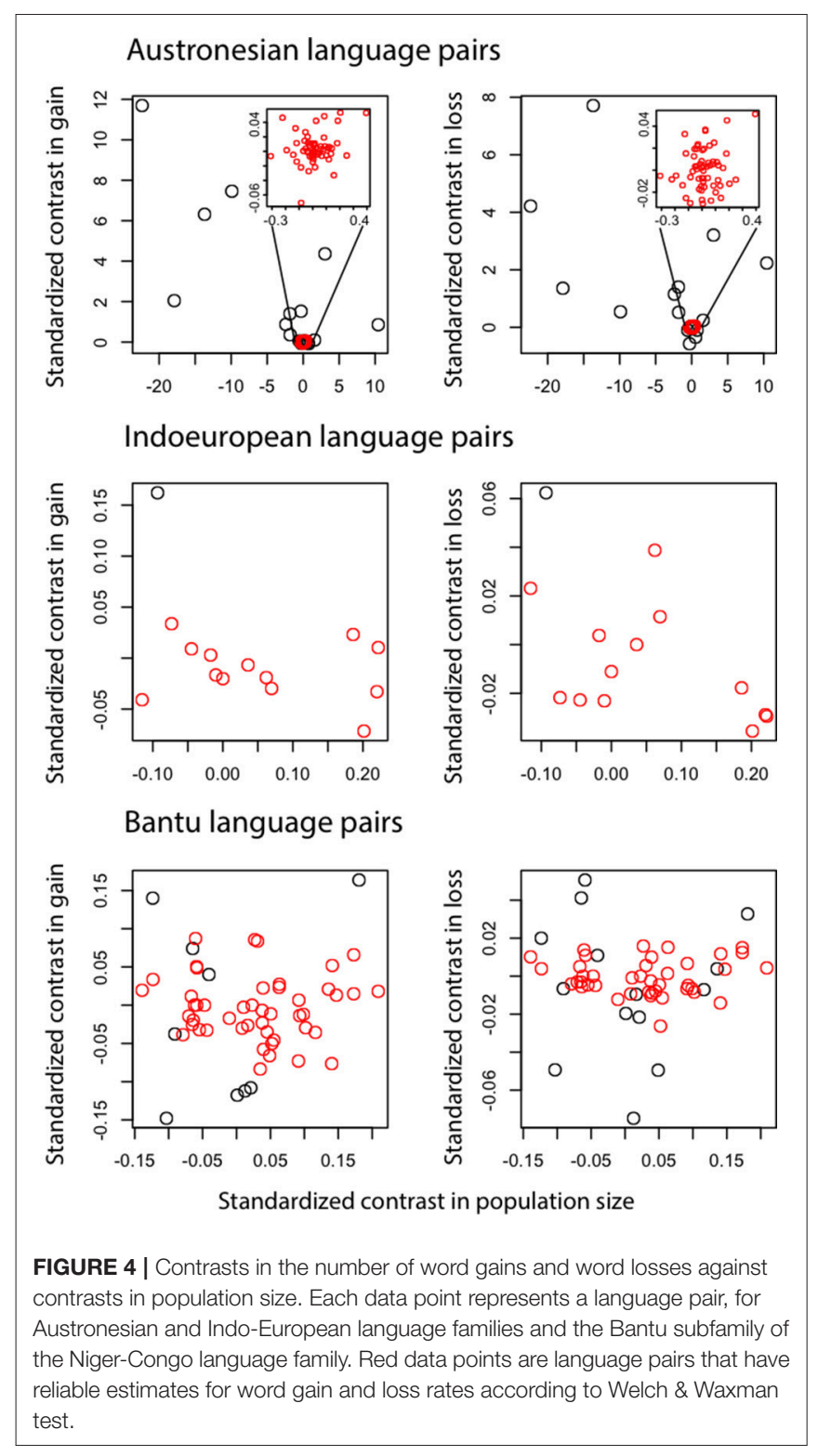

may eventually drift to fixation, leading to the loss of other variants at that locus (Charlesworth, 2009; Lanfear et al., 2014).

In contrast, the effects of population size on language evolution are not as straightforward to predict, and many alternative hypotheses have been suggested. Large populations of organisms generate more mutations per generation because there are more genomes in the population that can undergo change. Languages with large speaker populations might be expected to generate more innovations (Kline and Boyd, 2010; Collard et al., 2013), however unlike genetic mutation, the processes that create new language variants are not well understood, and may occur by a wider range of mechanisms. Unlike mutation, which is random with respect to utility, introduction of new language variants can be guided by perceived need, and can be regulated by social convention or top-down rules (see Bromham, 2017). Similarly, rates of language change may show different patterns to genetic
TABLE 6 | Overall statistics for the three cognate datasets showing the language group, source publication, word list size, average number of cognates per language ( \pm standard deviation) and average number of synonyms per lexical entry across languages ( \pm standard deviation).

\begin{tabular}{llccc}
\hline Family & Data source & Word list & Cognates & Synonyms \\
\hline Austronesian & Greenhill et al., 2008 & 210 & $198.91(31.25)$ & $0.95(0.15)$ \\
Indo-European & Bouckaert et al., 2012 & 207 & $223.46(20.95)$ & $1.08(0.10)$ \\
Bantu & Grollemund et al., 2015 & 100 & $91.17(12.29)$ & $0.91(0.12)$ \\
\hline
\end{tabular}

change if the process of substitution is by horizontal spread of variants through the population, rather than by inheritance (Reali and Griffiths, 2010). So, unlike adaptive genetic change in biological populations, it is possible that smaller speaker populations might have a greater rate of adoption of innovations because it is easier for new words to diffuse to all speakers and replace all other variants (Nettle, 1999). It is therefore difficult to predict whether smaller or larger speaker populations should have greater rates of language change, whether patterns should be the same or different for both gains and losses of language elements, and whether we expect similar patterns across all language families or more idiosyncratic associations, particular to given language groups.

Our analysis suggests that, as for Polynesian languages, smaller Indo-European languages have greater rates of word loss from basic vocabulary. This result is consistent with the claim that smaller populations are at greater risk of loss of language elements, and other aspects of culture, due to effects of incomplete sampling of variants over generations. However, we note that the relatively small sample size for this dataset complicates the interpretation of this result. Least squares regression after Welch \& Waxman test has the same false positive rate but has much less power than Poisson regression when sample size is small ( $\sim$ ten or fewer pairs, Hua et al., 2015). This makes it difficult to interpret the inconsistent results of these two analyses, as they may be due to their difference in the statistical power. Hence, the negative relationship between rates of loss and population size for Indo-European languages would benefit from additional investigation. We do not find evidence for a negative relationship between population size and word loss rates in the Austronesian and Bantu groups. This finding suggests that either these datasets contain too few language variants to have sufficient power to detect rate differences, or that the increased loss rate in small populations is not a universal phenomenon, or that it is a relatively weak force in some language groups and thus may be overwhelmed by other social, linguistic or demographic factors.

One factor that may be playing a role in the uncertainty in our results, and in the wider debate in general, is that measuring speech community size is notoriously difficult. How exactly does one delimit a speech community (Crystal, 2008) and what degree of proficiency in a language is sufficient to be part of the community (Bloomfield, 1933)? This task is made harder as there are few national censuses that collect detailed speaker statistics. Further, speaker population size can change rapidly with many modern world languages (especially 
the Indo-European languages) experiencing rapid growth over the last few hundred years (Crystal, 2008), while others have experienced catastrophic declines (Bowern, 2010). For the same reasons, the difficulty of obtaining accurate population estimates is also a problem in biology. Furthermore, the relevant parameter for genetic change-the effective population size-is difficult to estimate directly, even when accurate census information is available (Wang et al., 2016). Likewise, there may be an important role played by population and network density-tightknit networks may inhibit change, while loosely integrated speech communities (regardless of their size), may facilitate change (Granovetter, 1973; Milroy and Milroy, 1992). One way forward here is perhaps to simulate rates of change over a range of population sizes and network topologies (c.f. Reali et al., 2018).

Despite the obvious challenges in obtaining an accurate measure of speaker population size, several previous studies have reported that empirical estimates of population size do correlate with aspects of language change (Hay and Bauer, 2007; Lupyan and Dale, 2010; Bromham et al., 2015a). Therefore, either census population size, as reported in databases such as the Ethnologue, are sufficiently accurate reflections of speaker population size that they are able to reveal significant patterns of language change, or census population size is reflecting some aspect of languages that is connected to change. In either case, the reported relationships with speaker population size invite further investigation.

We can draw two conclusions from these results. Firstly, we provide some evidence that rates of language change can be affected by demographic factors. Even if the effect is not universal, the finding of significant associations between population size and patterns of linguistic change in some languages urges caution for any analysis of language evolution that makes an assumption of uniform rates of change. These results also potentially provide a window on processes of language change in these lineages, providing further impetus to investigate the effect of number of speakers on patterns of language transmission and loss. A more detailed study of language change for a larger number of comparisons might clarify the relationship between population size and word loss rates, particularly within the Indo-European language family.

Secondly, we have shown that the significant patterns of language change identified in a previous study are not a universal phenomenon. Unlike the study of Polynesian languages, we did not find any significant relationships between word gain rate and population size, and the association between loss rates and population size was not evident for all language families analyzed. The lack of universal relationships suggests that it may be difficult to draw general conclusions about the influence of demographic factors on patterns and rates of language change. Many other factors have been proposed to influence rates of language change (Greenhill, 2014) including population density, social structure (Nettle, 1999; Labov, 2007; Ke et al., 2008; Trudgill, 2011), degree of contact, and connectedness with other languages (Matras, 2009; Bowern, 2010), degree of language diffusion within a speech community (Wichmann et al., 2008), degree of bilingualism or multilingualism (Lupyan and Dale, 2010; Bentz and Winter, 2013), language group diversity (Atkinson et al., 2008) and environmental factors such as habitat heterogeneity and latitude (Bowern, 2010; Blust, 2013; Amano et al., 2014). These factors might mediate or overwhelm the effect of speaker population size.

We find no evidence to support the hypothesis that uptake of new words should be faster in small populations, which is based on the assumption that new words can diffuse more efficiently through a smaller speaker population than a larger one (Nettle, 1999). Nor do we find support for the suggestion that large, widespread languages have a tendency to lose linguistic features a greater rate (Lupyan and Dale, 2010). However, this latter hypothesis is predominantly expected to explain loss of complex linguistic morphology (such as case systems), which may be harder for non-native speakers to learn, rather than basic vocabulary studied here which may be comparatively easier for second language learners to acquire (but see Kempe and Brooks, 2018). Further, our results cannot be interpreted as confirmation of previous studies that suggest there is no effect of population size on rates (Wichmann and Holman, 2009). The detection of significant patterns in rates of lexical change with population size variation in the Polynesian and Indo-European languages, but the failure to identify similar patterns in the Bantu and Austronesian data, suggests that patterns of rates may need to be investigated on a case-by-case basis.

The failure to find a consistent association between population size and rate of change for languages means that analogies drawn between biological and linguistic evolution must be carefully considered to make sure that they are appropriate for linguistic evolution (Bowern and Evans, 2014). For example, patterns of human migration can leave similar traces on both genetic and linguistic diversity (Hurles et al., 2003; Hunley et al., 2007, 2008; Longobardi et al., 2015), but even though the patterns are the same, the underlying mechanisms may not be identical. The observation of decreasing phoneme inventories along chains of human migration has been attributed to serial founder effects (Trudgill, 2004; Atkinson, 2011). While founder effect is likely to influence genetic variability, because a small number of colonists cannot carry all of the genetic variation of the parent population, it might not have the same effect on language variants, as the founding population may use all the main variants in basic vocabulary. Similarly, while a correlation between lineage diversity and rate of change has been reported for both genetic and linguistic evolution (Pagel et al., 2006; Atkinson et al., 2008; Lanfear et al., 2010; Bromham et al., 2015a), it may not reflect a shared mechanism: while formation of new languages may drive higher rates of word turnover, speciation itself is unlikely to drive faster mutation rates in molecular evolution. Our results suggest that the population size effects may be another example of a pattern that is superficially similar between linguistic and biological evolution, yet may be driven by different mechanisms.

However, although the processes underlying language change and genetic change may be different, many of the same analytical tools can be used in the study of both biological and language evolution (see Bromham, 2017). This point was well recognized by early promoters of cross-disciplinary dialogue between evolutionary biology and historical linguistics (Morpugo Davies, 1975), such as Charles Darwin, August Schleicher, and Charles Lyell (Lyell, 1863; Schleicher, 1869; Darwin, 1871). For example, 
Schleicher's analogy between borrowing from a foreign language and biological cross-breeding did not imply the same mechanism for both, yet both have the effect of confounding attempts to represent evolutionary history as a bifurcating phylogeny (List et al., 2014). Yet the same solutions may apply to both processes, regardless of their mechanistic origin, such as representation of relationships as a network rather than a tree. Similarly, the shared problem of phylogenetic non-independence due to shared inheritance applies to both languages and species despite the many differences in mode of evolutionary change. While some solutions may be more readily applied to cross-species analysis, due to the availability of phylogenies for many groups, other solutions can be applied more readily to both languages and species, even in the absence of a phylogeny. We demonstrate here that sister pairs analysis is a viable solution to Galton's problem, and it can be applied using information from widely available language taxonomies.

\section{CONCLUSION}

Our results show that some of the variation of rates of lexical change in languages can, in some cases, be attributable to differences in speaker population size. Significant correlations between population size and rate of word loss were identified for Indo-European languages, but not for Austronesian and Bantu languages. One possible explanation for the negative relationship between speaker population size and loss rates is that language

\section{REFERENCES}

Amano, N., Piper, P. J., Hung, H.-C., and Bellwood, P. (2013). Introduced domestic animals in the neolithic and metal age of the Philippines: evidence from Nagsabaran, Northern Luzon. J. Island Coast. Archaeol. 8, 317-335. doi: 10.1080/15564894.2013.781084

Amano, T., Sandel, B., Eager, H., Bulteau, E., Svenning, J. C., Dalsgaard, B., et al. (2014). Global distribution and drivers of language extinction risk. Proc. R. Soc. B Biol. Sci. 281:20141574. doi: 10.1098/rspb.2014.1574

Anthony, D. W., and Ringe, D. (2015). The Indo-European homeland from linguistic and archaeological perspectives. Annu. Rev. Linguist. 1, 199-219. doi: 10.1146/annurev-linguist-030514-124812

Atkinson, Q. D. (2011). Phonemic diversity supports a serial founder effect model of language expansion from Africa. Science 332, 346-349. doi: 10.1126/science.1199295

Atkinson, Q. D., Meade, A., Venditti, C., Greenhill, S. J., and Pagel, M. (2008). Languages evolve in punctuational bursts. Science 319:588. doi: $10.1126 /$ science. 1149683

Baldini, R. (2015). Revisiting the effect of population size on cumulative cultural evolution. J. Cogn. Cult. 15, 320-336. doi: 10.1163/15685373-12342153

Bentley, R. A., Hahn, M. W., and Shennan, S. J. (2004). Random drift and culture change. Proc. R. Soc. Lond. Series B Biol. Sci. 271, 1443-1450. doi: $10.1098 /$ rspb.2004.2746

Bentley, R. A., Lipo, C. P., Herzog, H. A., and Hahn, M. W. (2007). Regular rates of popular culture change reflect random copying. Evol. Hum. Behav. 28, 151-158. doi: 10.1016/j.evolhumbehav.2006.10.002

Bentz, C., and Winter, B. (2013). Languages with more second language learners tend to lose the nominal case. Lang. Dyn. Change 3, 1-27. doi: 10.1163/22105832-13030105

Bergsland, K., and Vogt, H. (1962). On the validity of glottochronology. Curr. Anthropol. 3, 115-153. doi: 10.1086/200264 evolution shares similar mechanisms with genetic evolution, because both show patterns of greater rates of loss of variation in small populations. However, the lack of significant relationships between word gain and loss in two other large language groupsAustronesian and Bantu-warns that we cannot reliably predict variation in rates of linguistic evolution by extrapolation from general principles. By demonstrating that differences can exist in rates of change even between closely related languages, our results caution against assuming uniform rates of change across all languages, and suggest that in some cases the rates of change may be consistently influenced by demographic factors.

\section{AUTHOR CONTRIBUTIONS}

$\mathrm{LB}, \mathrm{CW}, \mathrm{XH}$, and SG: Conceived the project and wrote the paper; SG, CW, and HS: Collected data; XH: Analyzed data.

\section{FUNDING}

ARC Centre of Excellence for the Dynamics of Language (CE140100041).

\section{ACKNOWLEDGMENTS}

We thank Noel Amano, Cormac Anderson, Chiara Barbieri, Nick Evans, Russell Gray, Rebecca Grollemund, and Aymeric Hermann for their assistance and encouragement.

Berniell-Lee, G., Calafell, F., Bosch, E., Heyer, E., Sica, L., Mouguiama-Daouda, P., et al. (2009). Genetic and demographic implications of the bantu expansion: insights from human paternal lineages. Mol. Biol. Evol. 26, 1581-1589. doi: $10.1093 / \mathrm{molbev} / \mathrm{msp} 069$

Blasi, D., Michaelis, S. M., and Haspelmath, M. (2017). Grammars are robustly transmitted even during the emergence of creole languages. Nat. Hum. Behav. 1, 723-729. doi: 10.1038/s41562-017-0192-4

Bloomfield, L. (1933). Language. London: Allen \& Unwin.

Blust, R. (2000). "Why lexicostatistics doesn't work: the 'universal constant' hypothesis and the Austronesian languages," in Time Depth in Historical Linguistics, eds C. Renfrew, A. McMahon, and L. Trask (Cambridge: McDonald Institute for Archaeological Research), 311-331.

Blust, R. (2013). The Austronesian Languages. Canberra, ACT: Asia-Pacific Linguistics.

Blust, R. (2015). "Southeast Asian islands and oceania: Austronesian linguistic history,"in The Global Prehistory of Human Migration, ed P. Bellwood (New Jersey, NJ: Wiley-Blackwell), 276-283.

Bouckaert, R., Lemey, P., Dunn, M., Greenhill, S. J., Alekseyenko, A. V., Drummond, A. J., et al. (2012). Mapping the origins and expansion of the Indo-European language family. Science 337, 957-960. doi: 10.1126/science. 1219669

Bowern, C. (2010). Correlates of language change in hunter-gatherer and other 'small' languages. Lang. Linguist. Compass 4, 665-679. doi: 10.1111/j.1749-818X.2010.00220.x

Bowern, C., and Evans, B. (2014). "Foundations of the new historical linguistics," in The Routledge Handbook of Historical Linguistics, eds C. Bowern and B. Evans (London: Routledge), 1-42.

Bromham, L. (2016). Testing hypotheses in macroevolution. Stud. Hist. Philos. Sci. A 55, 47-59. doi: 10.1016/j.shpsa.2015.08.013

Bromham, L. (2017). Curiously the same: swapping tools between linguistics and evolutionary biology. Biol. Philos. 32, 855-886. doi: 10.1007/s10539-017-9594-y 
Bromham, L., Rambaut, A., Hendy, M. D., and Penny, D. (2000). The power of relative rates tests depends on the data. J. Mol. Evol. 50, 296-301. doi: $10.1007 / \mathrm{s} 002399910034$

Bromham, L., Hua, X., Fitzpatrick, T. G., and Greenhill, S. J. (2015a). Rate of language evolution is affected by population size. Proc. Natl. Acad. Sci. U.S.A. 112, 2097-2102. doi: 10.1073/pnas.1419704112

Bromham, L., Hua, X., Lanfear, R., and Cowman, P. (2015b). Exploring the relationships between mutation rates, life history, genome size, environment and species richness in flowering plants. Am. Nat. 185, 507-524. doi: $10.1086 / 680052$

Caldwell, C. A., and Millen, A. E. (2010). Human cumulative culture in the laboratory: effects of (micro) population size. Learn. Behav. 38, 310-318. doi: 10.3758/LB.38.3.310

Chang, W., Cathcart, C., Hall, D., and Garrett, A. (2015). Ancestry-constrained phylogenetic analysis supports the Indo-European steppe hypothesis. Language 91, 194-244. doi: 10.1353/lan.2015.0005

Charlesworth, B. (2009). Effective population size and patterns of molecular evolution and variation. Nature 10, 195-205. doi: 10.1038/nrg2526

Collard, M., Ruttle, A., Buchanan, B., and O’Brien, M. J. (2013). Population size and cultural evolution in nonindustrial food-producing societies. PLOS ONE 8:e72628. doi: 10.1371/journal.pone.0072628

Crystal, D. (2008). Two thousand million? Engl. Today 24, 3-6. doi: $10.1017 /$ S0266078408000023

Currie, T. E., Meade, A., Guillon, M., and Mace, R. (2013). Cultural phylogeography of the Bantu languages of sub-Saharan Africa. Proc. R. Soc. B Biol. Sci. 280:20130695. doi: 10.1098/rspb.2013.0695

Darwin, C. (1871). The Descent of Man, and Selection in Relation to Sex. London: John Murray.

de Filippo, C., Bostoen, K., Stoneking, M., and Pakendorf, B. (2012). Bringing together linguistic and genetic evidence to test the Bantu expansion. Proc. $R$. Soc. B Biol. Sci. 279, 3256-3263. doi: 10.1098/rspb.2012.0318

Derex, M., Beugin, M. P., Godelle, B., and Raymond, M. (2013). Experimental evidence for the influence of group size on cultural complexity. Nature 503, 389-391. doi: 10.1038/nature12774

Derksen, R. (2008). Etymological Dictionary of the Slavic Inherited Lexicon. Leiden: Brill.

Durie, M., and Ross, M. D. (1996). The Comparative Method Reviewed: Regularity and Irregularity in Language Change. Oxford: Oxford University Press.

Felsenstein, J. (1985). Phylogenies and the comparative method. Am. Nat. 125, 1-15. doi: $10.1086 / 284325$

Gavin, M. C., Botero, C. A., Bowern, C., Colwell, R. K., Dunn, M., Dunn, R. R., et al. (2013). Toward a mechanistic understanding of linguistic diversity. Bioscience 63, 524-535. doi: 10.1525/bio.2013.63.7.6

Gavin, M. C., and Sibanda, N. (2012). The island biogeography of languages. Glob. Ecol. Biogeogr. 21, 958-967. doi: 10.1111/j.1466-8238.2011.00744.x

Geertz, C. (1959). Form and variation in balinese village structure. Am. Anthropol. 61, 991-1012. doi: 10.1525/aa.1959.61.6.02a00060

Goodenough, W. H. (1957). Oceania and the problem of controls in the study of cultural and human evolution. J. Polyn. Soc. 66, 146-155.

Granovetter, M. S. (1973). The strength of weak ties. Am. J. Sociol. 78, 1360-1380. doi: $10.1086 / 225469$

Gray, R. D., and Atkinson, Q. D. (2003). Language-tree divergence times support the Anatolian theory of Indo-European origin. Nature 426, 435-439. doi: 10.1038 /nature02029

Gray, R. D., Atkinson, Q. D., and Greenhill, S. J. (2011). Language evolution and human history: what a difference a date makes. Philos. Trans. R. Soc. B Biol. Sci. 366, 1090-1100. doi: 10.1098/rstb.2010.0378

Gray, R. D., Drummond, A. J., and Greenhill, S. J. (2009). Language phylogenies reveal expansion pulses and pauses in pacific settlement. Science 323, 479-483. doi: $10.1126 /$ science. 1166858

Greenhill, S. J. (2014). "Demographic correlates of language diversity," in Routledge Handbook of Historical Linguistics, eds C. Bowern and B. Evans (London: Routledge), 555-578.

Greenhill, S. J., Blust, R., and Gray, R. D. (2008). The Austronesian basic vocabulary database: from bioinformatics to lexomics. Evol. Bioinformat. 4, 271-283. doi: 10.4137/EBO.S893

Grollemund, R., Branford, S., Bostoen, K., Meade, A., Venditti, C., and Pagel, M. (2015). Bantu expansion shows that habitat alters the route and pace of human dispersals. Proc. Natl. Acad. Sci. U.S.A. 112, 13296-13301. doi: 10.1073/pnas.1503793112

Haak, W., Lazaridis, I., Patterson, N., Rohland, N., Mallick, S., Llamas, B., et al. (2015). Massive migration from the steppe was a source for Indo-European languages in Europe. Nature 522, 207-211. doi: 10.1038/nature14317

Hammarström, H., Forkel, R., Haspelmath, M., and Bank, S. (2016). Glottolog. 2.7. Available online at: http://glottolog.org (Accessed August 05, 2017).

Harvey, P. H., and Pagel, M. (1991). The Comparative Method in Evolutionary Biology. Oxford: Oxford University Press.

Hay, J., and Bauer, L. (2007). Phoneme inventory size and population size. Language 83, 388-400. doi: 10.1353/lan.2007.0071

Henrich, J. (2004). Demography and cultural evolution: how adaptive cultural processes can produce maladaptive losses: the tasmanian case. Am. Antiq. 69, 197-214. doi: $10.2307 / 4128416$

Hoijer, H. (1956). Lexicostatistics: a critique. Language 32, 49-60. doi: $10.2307 / 410652$

Hua, X., Cowman, P., Warren, D., and Bromham, L. (2015). Longevity is linked to mitochondrial mutation rates in rockfish: a test using poisson regression. $\mathrm{Mol}$. Biol. Evol. 32, 2633-2645. doi: 10.1093/molbev/msv137

Hung, H.-C., Carson, M. T., Bellwood, P., Campos, F. Z., Piper, P. J., Dizon, E., et al. (2011). The first settlement of remote Oceania: the Philippines to the Marianas. Antiquity 85, 909-926. doi: 10.1017/S0003598X00068393

Hunley, K. L., Cabana, G. S., Merriwether, D. A., and Long, J. C. (2007). A formal test of linguistic and genetic coevolution in native central and South America. Am. J. Phys. Anthropol. 132, 622-631. doi: 10.1002/ajpa.20542

Hunley, K., Dunn, M., Lindström, E., Reesink, G., Terrill, A., Healy, M. E., et al. (2008). Genetic and linguistic coevolution in Northern Island Melanesia. PLoS Genet. 4:e1000239. doi: 10.1371/journal.pgen.1000239

Hurles, M. E., Matisoo-Smith, E., Gray, R. D., and Penny, D. (2003). Untangling oceanic settlement: the edge of the knowable. Trends Ecol. Evol. 18, 531-540. doi: 10.1016/S0169-5347(03)00245-3

Jay, R. R. (1969). Javanese Villagers: Social Relations in Rural Modjokuto. Cambridge, MA: MIT Press.

Johnson, L. (1976). A rate of change index for language. Lang. Soc. 5, 165-172. doi: $10.1017 /$ S0047404500007004

Ke, J. Y., Gong, T., and Wang, W. S. Y. (2008). Language change in social networks. Commun. Comput. Phys. 3, 935-949.

Kempe, V., and Brooks, P. J. (2018). Linking adult second language learning and diachronic change: a cautionary note. Front. Psychol. 9:480 doi: $10.3389 /$ fpsyg. 2018.00480

Kirch, P. V., and Green, R. C. (1987). History, phylogeny, and evolution in Polynesia. Curr. Anthropol. 28, 431-456. doi: 10.1086/203547

Kline, M. A., and Boyd, R. (2010). Population size predicts technological complexity in Oceania. Proc. R. Soc. B Biol. Sci. 277, 2559-2564. doi: $10.1098 /$ rspb.2010.0452

Ko, A. M., Chen, C. Y., Fu, Q., Delfin, F., Li, M., Chiu, H. L., et al. (2014). Early austronesians: into and out of Taiwan. Am. J. Hum. Genet. 94, 426-436. doi: 10.1016/j.ajhg.2014.02.003

Labov, W. (2007). Transmission and diffusion. Language 83, 344-387. doi: $10.1353 /$ lan.2007.0082

Lanfear, R., Ho, S. Y. W., Love, D., and Bromham, L. (2010). Mutation rate influences diversification rate in birds. Proc. Natl. Acad. Sci. U.S.A. 107, 20423-20428. doi: 10.1073/pnas.1007888107

Lanfear, R., Kokko, H., and Eyre-Walker, A. (2014). Population size and the rate of evolution. Trends Ecol. Evol. 29, 33-41. doi: 10.1016/j.tree.2013.09.009

Lev-Ari, S. (2017). Talking to fewer people leads to having more malleable linguistic representations. PLOS ONE 12:e0183593. doi: 10.1371/journal.pone.0183593

Levinson, S. C., and Gray, R. D. (2012). Tools from evolutionary biology shed new light on the diversification of languages. Trends Cogn. Sci. 16, 167-173. doi: $10.1016 /$ j.tics.2012.01.007

Lewis, P. M., Simons, G. F., and Fennig, C. D. (2015). Ethnologue: Languages of the World. Dallas, TX: SIL International.

Li, S., Schlebusch, C., and Jakobsson, M. (2014). Genetic variation reveals large-scale population expansion and migration during the expansion of Bantu-speaking peoples. Proc. R. Soc. B Biol. Sci. 281:20141448. doi: $10.1098 /$ rspb.2014.1448

List, J. M., Nelson-Sathi, S., Geisler, H., and Martin, W. (2014). Networks of lexical borrowing and lateral gene transfer in language 
and genome evolution. Bioessays 36, 141-150. doi: 10.1002/bies.201 300096

Longobardi, G., Ghirotto, S., Guardiano, C., Tassi, F., Benazzo, A., Ceolin, A., et al. (2015). Across language families: genome diversity mirrors linguistic variation within Europe. Am. J. Phys. Anthropol. 157, 630-640. doi: 10.1002/ajpa.22758

Lupyan, G., and Dale, R. (2010). Language structure is partly determined by social structure. PLoS ONE 5:e8559. doi: 10.1371/journal.pone.0008559

Lyell, C. (1863). The Geological Evidence of the Antiquity of Man. London: John Murray.

Matras, Y. (2009). Language Contact. Cambridge: Cambridge University Press.

Milroy, J., and Milroy, L. (1985). Linguistic change, social network and speaker innovation. J. Linguist. 21, 339-384. doi: 10.1017/S0022226700010306

Milroy, L., and Milroy, J. (1992). Social network and social class: toward an integrated sociolinguistic model. Lang. Soc. 21, 1-26. doi: 10.1017/S0047404500015013

Montano, V., Ferri, G., Marcari, V., Batini, C., Anyaele, O., Destro-Bisol, G., et al. (2011). The Bantu expansion revisited: a new analysis of $\mathrm{Y}$ chromosome variation in Central Western Africa. Mol. Ecol. 20, 2693-2708. doi: 10.1111/j.1365-294X.2011.05130.x

Moran, S., McCloy, D., and Wright, R. (2012). Revisiting population size vs. phoneme inventory size. Language 88, 877-893. doi: 10.1353/lan.2012.0087

Morpugo Davies, A. (1975). "Language classification in the nineteenth century," in Current Trends in Linguistics, Vol. 13, ed T. A. Sebeok (The Hague: Mouton), 607-716.

Neiman, F. D. (1995). Stylistic variation in evolutionary perspective: inferences from decorative diversity and interassemblage distance in Illinois woodland ceramic assemblages. Am. Antiq. 60, 7-36. doi: 10.2307/282074

Nettle, D. (1999). Is the rate of linguistic change constant? Lingua 108, 119-136. doi: 10.1016/S0024-3841(98)00047-3

Nettle, D. (2012). Social scale and structural complexity in human languages. Philos. Trans. R. Soc. Lond. B Biol. Sci. 367, 1829-1836. doi: $10.1098 /$ rstb.2011.0216

Pagel, M., Venditti, C., and Meade, A. (2006). Large punctuational contribution of speciation to evolutionary divergence at the molecular level. Science 314, 119-121. doi: 10.1126/science.1129647

Pakendorf, B., de Filippo, C., and Bostoen, K. (2011). Molecular Perspectives on the Bantu expansion: a synthesis. Lang. Dyn. Change 1, 50-88. doi: 10.1163/221058211X570349

Paul, H. (1880). Prinzipien der Sprachgeschichte. Halle: Max Niemeyer.

Pawley, A. (1967). The relationships of Polynesian outlier languages. J. Polyn. Soci. 76, 259-296.

Rea, J. A. (1958). Concerning the validity of lexicostatistics. Int. J. Am. Linguist. 24, 145-150. doi: 10.1086/464447

Read, D. (2012). Population size does not predict artifact complexity: analysis of data from Tasmania, Arctic hunter-gatherers, and Oceania fishing groups. Hum. Comp. Syst. UCLA. Available online at: https://escholarship.org/uc/item/ 61n4303q\#author

Reali, F., and Griffiths, T. L. (2010). Words as alleles: connecting language evolution with Bayesian learners to models of genetic drift. Proc. R. Soc. B Biol. Sci. 277, 429-436. doi: 10.1098/rspb.2009.1513

Reali, F., Chater, N., and Christiansen, M. H. (2018). Simpler grammar, larger vocabulary: how population size affects language. Proc. R. Soc. B Biol. Sci. 285:20172586. doi: 10.1098/rspb.2017.2586

Renfrew, C. (1987). Archaeology and Language: The Puzzle of Indo-European Origins. London: Cape.

Richerson, P. J., Boyd, R., and Bettinger, R. L. (2009). Cultural innovations and demographic change. Hum. Biol. 81, 211-235. doi: 10.3378/027.081.0306

Roberts, S., and Winters, J. (2013). Linguistic diversity and traffic accidents: lessons from statistical studies of cultural traits. PLOS ONE 8:e70902. doi: 10.1371/journal.pone.0070902
Sankoff, D. (1970). On the rate of replacement of word-meaning relationships. Language 46, 564-569. doi: 10.2307/412307

Schleicher, A. (1869). Darwinism Tested by the Science of Language. London: John Camden Hotton.

Shennan, S. (2001). Demography and cultural innovation: a model and its implications for the emergence of modern human culture. Camb. Archaeol. J. 11, 5-16. doi: 10.1017/S0959774301000014

Shennan, S. J., and Wilkinson, J. R. (2001). Ceramic style change and neutral evolution: a case study from Neolithic Europe. Am. Antiq. 577-593. doi: $10.2307 / 2694174$

Spriggs, M. (2010). "I was so much older then, I'm younger than that now': why the dates keep changing for the spread of Austronesian languages a journey through Austronesian and Papuan linguistic and cultural space papers," in Honour of Andrew Pawley, eds J. Bowden, N. P. Himmelmann, and M. D. Ross (Canberra, ACT: Pacific Linguistics), $113-140$.

Spriggs, M. (2011). Archaeology and the Austronesian expansion: where are we now ? Antiquity 85, 510-528. doi: 10.1017/S0003598X000 67910

Swadesh, M. (1952). Lexico-statistic dating of prehistoric ethnic contacts: with special reference to North American Indians and Eskimos. Proc. Am. Philos. Soc. 96, 452-463.

Swadesh, M. (1955). Towards greater accuracy in lexicostatistic dating. Int. J. Am. Linguist. 21, 121-137. doi: 10.1086/464321

Tajima, F. (1993). Simple methods for testing the molecular evolutionary clock hypothesis. Genetics 135, 599-607.

Thomason, S. G., and Kaufman, T. (1988). Language Contact, Creolization, and Genetic Linguistics. California: University of California Press.

Trudgill, P. (2004). Linguistic and social typology: the Austronesian migration and phoneme inventories. Linguist. Typol. 8, 305-320. doi: 10.1515/lity.2004.8. 3.305

Trudgill, P. (2011). Sociolinguistic Typology: Social Determinants of Linguistic Complexity. Oxford: Oxford University Press.

Wang, J., Santiago, E., and Caballero, A. (2016). Prediction and estimation of effective population size. Heredity 117, 193-206. doi: 10.1038/hdy.20 16.43

Welch, J. J., and Waxman, D. (2008). Calculating independent contrasts for the comparative study of substitution rates. J. Theor. Biol. 251, 667-678. doi: 10.1016/j.jtbi.2007.12.015

Wichmann, S., and Holman, E. W. (2009). Population size and rates of language change. Hum. Biol. 81, 259-274. doi: 10.3378/027.081.0308

Wichmann, S., Rama, T., and Holman, E. W. (2011). Phonological diversity, word length, and population sizes across languages: the ASJP evidence. Linguist. Typol. 15, 177-197. doi: 10.1515/lity.20 11.013

Wichmann, S., Stauffer, D., Schulze, C., and Holman, E. W. (2008). Do language change rates depend on population size? Adv. Comp. Syst. 11, 357-369. doi: 10.1142/S0219525908001684

Conflict of Interest Statement: The authors declare that the research was conducted in the absence of any commercial or financial relationships that could be construed as a potential conflict of interest.

Copyright (c) 2018 Greenhill, Hua, Welsh, Schneemann and Bromham. This is an open-access article distributed under the terms of the Creative Commons Attribution License (CC BY). The use, distribution or reproduction in other forums is permitted, provided the original author(s) and the copyright owner are credited and that the original publication in this journal is cited, in accordance with accepted academic practice. No use, distribution or reproduction is permitted which does not comply with these terms. 